\title{
Measuring Social Integration among Patients with Schizophrenia: Testing the Reliability of the Social Integration Scale in a Non-Western Setting
}

\author{
Ogundare $\mathrm{T}^{*}$ and Onifade PO
}

Neuropsychiatric Hospital, Aro, PMB 2002, Abeokuta, Ogun State, Nigeria

*Corresponding author: Ogundare T, Neuropsychiatric Hospital, Aro, PMB 2002, Abeokuta, Ogun State, Nigeria, Tel: +1 617-358-4095; E-mail: ogundare@bu.edu

Received date: October 23, 2019; Accepted date: December 10, 2019; Published date: December 17, 2019

Citation: Ogundare T, Onifade PO (2019) Measuring Social Integration among Patients with Schizophrenia: testing the reliability of the Social Integration Scale in a Non-Western Setting. Clin Psychiatry Vol.5 No.3:64.

\section{Abstract}

Background: Social integration is a multidimensional construct that is thought to include both the behavioral component of active engagement in a wide range of activities and/or social relationships and the cognitive component of a sense of communality and identification with one's social roles. Patients with schizophrenia have been described as being 'in the community but not of the community'. Although patients with schizophrenia have adequate social networks, their level of engagement is low.

Aim: To determine the social integration of patients with schizophrenia using the Social Integration Scale, and to determine the feasibility of using the Social Integration Scale in a non-western country.

Methods: This study was conducted among outpatients with schizophrenia attending the Out-Patient Clinic of the Neuropsychiatric Hospital, Abeokuta, Nigeria, aged 18-65 years. MINI-PLUS, PANSS, WHOQOL-BREF and SIS were administered to consenting participants.

Results: The mean (SD) age of participants were 40.9 (9.0) years, $52 \%$ were males, $42 \%$ were single, the mean (SD) age of onset of illness was 29.1 (8.8) years, $48 \%$ of them had greater than 10 years of illness duration, and $90 \%$ has had multiple episodes. PANSS shows a mean (SD) PANSS positive scale score of 8.46 (2.94), mean (SD) overall QOL score of 3.88 (1.15) and mean (SD) general health score of 4.02 (1.08). The Cronbach's alpha of the SIS was 0.86 , and factor analysis yielded 4 factors: 1) community participation, 2) giving and receiving help; 3) connectedness, and 4) initiation of social interactions.

Conclusion: The SIS is a valid measure of social integration among patients with schizophrenia in Nigeria.

Keywords: Schizophrenia; Patients; Social integration; Neuropsychiatry

\section{Introduction}

Social integration is a multidimensional construct that is thought to include both the behavioral component of active engagement in a wide range of activities and/or social relationships and the cognitive component of a sense of communality and identification with one's social roles [1].

Several measures exist to measure different aspects of social integration and are broadly divided into four according to Brissette et al.: 1) Role-based measures: assesses the number of recognized social positions or social identities. The most widely used of these measures is Cohen's social network index. 2) Social participation measures: assesses the extent and frequency of social activities. Social participation suggests that activities in which integrated people engage in confer health benefits. These measures also assess the range of social ties as well. Examples of scales are the Welin Activity Scale and the Social Participation Scale. 3) Perceived integration measures: assesses the individual's view of their communality and usually inquiries about familiarity with the community and identification with social roles. The most widely used of these measures is the Malmo Influence, Contact, and Anchorage Measure (MICAM). 4) Complex indicators: they combine information about marital status, the number of social ties, and frequency of contact with friends and relatives and community involvement into a single summary index. The most widely used is the Berkman-Syme Social Network Index [1-6].

Other scales that do not fall under the four categories above include Interview Schedule for Social Interaction, Social Integration Scale, Social Support Questionnaire, Duke Social Support Index, Interpersonal Support Evaluation List, Social Provision Scale. These measures attempt to measure a part of the construct of social integration especially network size and social support [7-12].

Previous research done on the social integration of mentally ill patients has conceptualized social integration using two indicators: location and function. Location referring to a residence outside the psychiatric hospital i.e. amount of time spent in the community, while functioning includes the use of everyday goods and services and fulfillment of social roles. However, the scope of social integration is being expanded and 
was re-defined by Ware et al. as "a process, unfolding over time, through which individuals who have been psychiatrically disabled increasingly develop and exercise their capacities for connectedness and citizenship". Social integration has been limited to network structure and size but recent works have attempted to extend its scope to capture satisfaction and the reciprocity of the social interactions [13].

Patients with schizophrenia have been described as being 'in the community but not of the community' and studies have found that although patients with schizophrenia have adequate social networks, their level of engagement is low [13-15].

Our study aims to determine the social integration of patients with schizophrenia using the Social Integration Scale, a 13-item questionnaire developed by Aubry et al. in 1996 for use among patients with serious mental illness in Canada. In order to test the appropriateness of the instrument given the different cultural backgrounds between the west and Africa, we conducted a pilot study to test the feasibility of the Social Integration Scale for use in a non-western country [8].

\section{Method}

\section{Study setting and procedure}

This study was conducted as part of a larger study among outpatients with schizophrenia attending the Out-Patient Clinic of the Neuropsychiatric Hospital, Abeokuta, Nigeria. The inclusion criteria were: patients aged 18-65 years with a diagnosis of Schizophrenia, confirmed by MINI-PLUS, who did not have co-morbid substance use disorder or chronic medical conditions, and who could understand either English or Yoruba, the native language.

The hospital initially started in 1944 as an asylum for soldiers who were repatriated home due to mental illness after the Second World War. The current hospital, Aro was built in 1954 when the need for a modern hospital arose. It has a total capacity of 546 beds for inpatient care and its patients are drawn from all over Nigeria and the neighboring African countries. Patients who have been discharged from the inpatient service and those who have never been hospitalized before are seen at the out-patient clinic of the hospital, which runs daily from 9 am to $3 \mathrm{pm}$ on weekdays. On average, 150 patients are seen daily at the Out-Patient Clinic with about 60 patients being treated for schizophrenia.

Data was collected over a period of the course of 1 month in March 2016. Patients' medical records were perused on each clinic day, and those who meet the criteria are approached in the waiting room as they waited for their consultation and the purpose of the research study explained to them. Patients participated voluntarily and could opt-out at any time, and not participating did not affect the quality of care received. Consenting participants were taken through the informed consent form and their signatures obtained.
Fifty patients were recruited to participate in the study and the interviews were conducted in a quiet and private consultation room within the clinic complex.

\section{Data collection instruments}

Sociodemographic questionnaire: This was designed by the researchers and collected sociodemographic and clinical data on the participants. Questions included: age, ethnic group, religion, occupation, etc. Clinical information was gotten from the case notes of the participants.

The social integration scale: This is a 13 -item selfadministered questionnaire that asks respondents to rate the frequency of different kinds of social contact with neighbors ranging from superficial (e.g., saying hello) to closer forms of contact (e.g. going out on a special outing). Response alternatives vary from never (1) to frequently (5), with higher scores reflecting greater social integration. Cronbach's alpha for the measure was found to be 0.87 for persons with psychiatric disabilities [8].

Positive and negative symptoms scale: Positive and Negative Syndrome Scale (PANSS) is a 30-item, 7-point rating instrument developed by Kay et al. [16]. Each item on the PANSS is rated on a Likert scale from 1-7 representing increasing levels of psychopathology (1=absent, and $7=$ extreme). The score ranges from 7-49 for both the positive and negative scales and 16-112 for the general psychopathology scale. In addition to the three scales, a fourth scale the composite scale was developed to reflect the magnitude and direction of the positive and negative syndromes and to determine the preponderance of one over the other yielding a bipolar index that ranges from -42 to +42 [16]. Kay et al. found a coefficients for the positive and negative scales to be 0.73 and 0.83 respectively with both scales having a strong correlation with the composite scale which also yielded coefficient of similar magnitude. For the positive, negative, composite and general psychopathology scales, the test-retest Pearson correlations were 0.80 $(p<0.001), 0.68(p<0.01), 0.66(p<0.01)$ and $0.60(p<0.02)$ respectively [16].

World Health Organization Quality of Life-BREF (WHOQOLBREF): The WHOQOL-BREF is an abbreviated 26-item version of the WHOQOL-100 containing items that were extracted from the WHOQOL-100 field trial data. Data for the WHOQOLBREF field trial were collected using a cross-sectional design in 24 centers representing 23 countries including Nigeria. It contains one item from each of the 24 facets of QOL included in the WHOQOL-100, plus two 'benchmark' items from the general facet on overall $\mathrm{QOL}$ and general health. It has four domains: Physical health, Psychological, Social relations, and Environment. The scores are transformed on a scale from 0 to 100 to enable comparisons to be made between domains composed of unequal numbers of items. The values for Cronbach's alpha for the WHOQOL-BREF were acceptable (>0.7) for Domains 1, 2 and 4 i.e. physical health 0.82 , psychological 0.81 , environment 0.80 , but marginal for social relationships $0.68[17,18]$. 


\section{Translation and modification of social integration scale}

The predominant ethnic tribe of participants was Yoruba which necessitated the translation of the instrument into Yoruba. done by a process of iterative back-translation. First, a bilingual expert in the Federal University was consulted and translated the instrument into the Yoruba language. Then another independent expert translated the Yoruba version into English, and the two versions were compared for contextual and linguistic accuracy. Only when the panel had agreed that the newly translated version was identical to the original version was the Yoruba version adopted for use in the study. The interviews were conducted either in Yoruba or English according to the preference of the participants.

Certain wordings and examples were changed from the original version to reflect the difference in the cultural and physical and built environment of the study setting. For example, in item 3, "Gone with a neighbor on a social outing such as shopping, to a movie, or other similar kinds of event?", the examples were changed to 'going to the local market, or to a party or to watch a soccer game or similar event'. Similarly, item 5 'Helped a neighbor by looking after their home while they were away and taking care of such things as watering plants, gathering mail, or feeding pets?' the examples were changed to 'giving you a copy of their keys, or asking you to help look after their kids before they return home, or asking their kids to come to play at your house'. Also, item 8 'Assisted a neighbor with a household task such as a minor house repair, shoveling snow, mowing the lawn, or moving furniture?' the examples such as 'shoveling snow' and 'mowing the lawn' were replaced with 'helping with sanitation of the compound where you live'. Item 11 'Discussed with a neighbor such things as home repairs, gardening, or other matters related to improving a home?' was changed to 'plumbing, electrical issues, decorations or other matters related to improving a home'.

These changes reflect a difference in the culture and physical and built environment of the country. Nigeria is a tropical country and has two distinct weather - rainy and dry seasons, and as such questions such as 'shoveling snow' becomes inappropriate. Also, the built environment is different. Many people live in tenement buildings and occupy single rooms or a room and parlor in a complex with shared toilets and bathrooms. Also, those who live in apartments do so in houses comprising of 4-8 such apartments built in blocks of flats within an enclosed compound with or without surrounding walls. In addition, shopping is usually done in more traditional farmer's markets and shops scattered all over the metropolis rather than in designated shopping malls. It is often noteworthy that many cities in Nigeria do not have cinemas or theatres, and where they are present are not the major source of socialization. The major social gatherings comprise of wedding, funeral, and child-naming ceremonies. This uniqueness was taken into account in the administration of the Social Integration Scale without affecting the fundamental measurement of each item.

\section{Ethical approval}

The study was approved by the Neuropsychiatric Hospital Abeokuta Institutional Review Board where the research was carried out.

\section{Data analysis}

The data were analyzed using the Statistical Analytical Software (SAS) version 9.4. Descriptive statistics are presented as frequency distribution tables, and mean and standard deviation calculated. Cronbach's alpha was used to determine the internal consistency of the Social Integration Scale. A principal factor analysis was carried out with orthogonal and oblique rotations to determine the factor structure of the instrument after the Kaiser-Meyer-Olkin sampling adequacy was determined. Factor extraction was done using the principal axis factor method for all components with an eigenvalue of 1 or greater. Factor loading was determined for items with 0.4 or greater factor loading on one component and less than 0.4 on others [19].

\section{Results}

\section{Sociodemographic characteristics}

Table 1 summarizes the sociodemographic characteristics of the respondents. The age ranges of the participants were between 28 and 62 years, with a mean (SD) of 40.9 (9.0) years, 26 (52\%) were males, 21 (42\%) were single, 14 (28\%) were married, 43 (86\%) were from the Yoruba ethnic group, 40 (80\%) were Christians, 6 (12\%) had primary education, 25 (50\%) had secondary education, 19 (38\%) had post-secondary education, and 40 (80\%) were engaged in an employment (paid or unpaid).

Table 1: Sociodemographic characteristics.

\begin{tabular}{|l|c|}
\hline Variable & N (\%) \\
\hline Males & $26(52 \%)$ \\
\hline Females & $24(48 \%)$ \\
\hline Marital Status & $21(42 \%)$ \\
\hline Married & $29(58 \%)$ \\
\hline Single/Divorced/Widowed & \multicolumn{2}{|l|}{} \\
\hline Ethnicity & $43(86 \%)$ \\
\hline Yoruba & $7(14 \%)$ \\
\hline Others & $6(12 \%)$ \\
\hline Religion & $25(50 \%)$ \\
\hline Christianity & $10(20 \%)$ \\
\hline Islam & \\
\hline Education & \\
\hline Primary & \\
\hline Secondary & \\
\hline
\end{tabular}




\begin{tabular}{|c|c|}
\hline Postsecondary & $19(38 \%)$ \\
\hline \multicolumn{2}{|l|}{ Employment } \\
\hline Employed (including volunteer) & $40(80 \%)$ \\
\hline Unemployed & $7(14 \%)$ \\
\hline Student/Retired & $3(6 \%)$ \\
\hline \multicolumn{2}{|l|}{ Number of episodes of illness } \\
\hline 1 & $10(20 \%)$ \\
\hline 2 & $21(42 \%)$ \\
\hline$>2$ & $19(38 \%)$ \\
\hline \multicolumn{2}{|l|}{ Hospitalizations } \\
\hline None & $28(56 \%)$ \\
\hline 1 & $10(20 \%)$ \\
\hline 2 or more & $12(24 \%)$ \\
\hline Mean (SD) age of onset of illness (years) & $29.1(8.8)$ \\
\hline Mean (SD) duration of illness (years) & $11.9(8.1)$ \\
\hline
\end{tabular}

Regarding clinical characteristics, the mean (SD) age of onset of illness was 29.1 (8.8) years, with a mean (SD) duration of illness of 11.9 (8.1) years. $48 \%$ of them had greater than 10 years of illness duration, and $90 \%$ has had multiple episodes. $34 \%$ of the sample has had at least one hospitalization for their illness with 4 (8\%) having being hospitalized in the past year. Clinical severity as measured by the PANSS shows a mean (SD) PANSS positive scale score of 8.46 (2.94), mean (SD) PANSS negative scale score of 9.90 (5.54), and mean (SD) PANSS general psychopathology score of 18.04 (2.19). Quality of life scores revealed a mean (SD) overall QOL score of 3.88 (1.15) and mean (SD) general health score of 4.02 (1.08).

\section{Reliability of the social integration scale}

The Social Integration Scale was found to be acceptable by the participants who found it easy to understand and answer the questions, and that it was relevant to their everyday life. Cronbach's alpha was computed and was found to be 0.86 , which indicates a high correlation between the items and that the instrument was reliable. The mean (SD) total SIS score for the respondents in the study was found to be 28.6 (9.5).

\section{Factor analysis}

Firstly, the Kaiser-Meyer-Olkin measure of sampling adequacy was 0.8 which is above the acceptable value of 0.5 and shows that the sample size was adequate to enable factor analysis to be conducted. A principal component analysis was performed using ones as prior communality estimates. The principal axis method was used to extract the components and this was followed by a varimax (orthogonal) and oblique rotations. Using the criteria of retaining factors with eigenvalues $>1$, four factors were retained for rotation. Combined, these factors accounted for $68 \%$ of the total variance $(40 \%, 10 \%, 10 \%$, and $8 \%$ respectively).
Table 2 presents the items and factor loadings of the rotated pattern. In the final analysis, the oblique rotations gave a better factor structure. When interpreting the rotated patterns, an item is said to load on a given component if the factor loading is 0.40 or greater for that component and 0.40 or lesser for the other component. Using this criterion, items $3,7,8,9,10$ and 13 were found to load on factor 1 ; items 4,5 , 6, 11 were found to load on factor 2; items 2 and 12 were found to load on factor 3 and item 1 was found to load on factor 4 .

Table 2: Rotated Factor Pattern and Final Communality Estimates from Principal Component Analysis of the Social Integration Scale.

\begin{tabular}{|c|c|c|c|c|c|}
\hline Items & Factor 1 & Factor 2 & Factor 3 & Factor 4 & h2 \\
\hline Item 1 & 0.01 & 0.13 & 0.06 & 0.81 & 0.65 \\
\hline Item 2 & 0.01 & -0.15 & 0.94 & 0.15 & 0.81 \\
\hline Item 3 & 0.51 & 0.16 & 0.34 & 0.37 & 0.75 \\
\hline Item 4 & -0.01 & 0.92 & -0.2 & 0.22 & 0.74 \\
\hline Item 5 & -0.11 & 0.7 & 0.11 & 0.38 & 0.56 \\
\hline Item 6 & 0.12 & 0.64 & 0.12 & -0.16 & 0.64 \\
\hline Item 7 & 0.8 & -0.09 & 0.13 & -0.03 & 0.66 \\
\hline Item 8 & 0.8 & 0.16 & -0.2 & 0.06 & 0.71 \\
\hline Item 9 & 0.61 & 0.05 & 0.15 & -0.29 & 0.59 \\
\hline Item 10 & 0.94 & -0.09 & -0.12 & 0.05 & 0.75 \\
\hline Item 11 & 0.36 & 0.54 & 0.01 & -0.3 & 0.76 \\
\hline Item 12 & -0.13 & 0.36 & 0.61 & -0.3 & 0.74 \\
\hline Item 13 & 0.45 & 0.01 & 0.36 & 0.11 & 0.46 \\
\hline Note: N=50. h2=communality estimates. Bold values factor loading $\geq 0.4$. \\
\hline
\end{tabular}

\section{Discussion}

This study was carried out to determine the feasibility of the use of the Social Integration Scale for the measurement of social integration among patients with schizophrenia in a nonwestern situation. Our study found that the Social Integration Scale presents a valid and reliable tool for measuring social integration. In this study the mean (SD) social integration score was 28.6 (9.5) which is slightly higher than the mean score reported in the study by Aubry et al. among patients with schizophrenia in Canada. The outcome of schizophrenia has been found to be better in developing countries compared with developed countries, and the extended family structure has been found to play a role. It may be that the better level of social integration in this study was as a result of the role of the extended family in the treatment and subsequent rehabilitation of patients with schizophrenia, but it may also be due to the about two-decade lag between this study and the study by Aubry et al. and in that time, psychiatric services have greatly improved, with consequently improved outcomes for patients with schizophrenia [8,20-22]. 
We reported a Cronbach's alpha of 0.86 , which is similar to that reported by Aubry et al. which shows that the instrument was reliable and showed a high correlation of the items making it suitable for use in this population. The factor analysis yielded a four-factor structure of the instrument which shows multidimensionality to the construct of social integration. From the four-factor structure, four dimensions of social integration can be measured namely: 1) community participation which involves participation in roles that fosters interaction with others and community belongingness; 2) giving and receiving help; 3) connectedness which encompasses the ability to form bonds with people who are not psychiatrically disabled and 4) initiation of social interactions. These constructs derive from the works of Ware et al. in using the capacities approach to the definition of social integration. This four-dimensional factor structure has not been previously tested in other patient populations and the original design of the Social Integration Scale did not include any factor to it. Therefore, there is a need for further research among different populations and with a larger sample size in the same and other populations to further ascertain the validity of the four-factor structure of the Social Integration Scale as proposed in this study $[8,13]$.

The major limitation of this study is the limited sample size, consisting of only 50 patients. Several theories exist as to the appropriate number needed for factor analysis with many proposing between 3 and 20 respondents per variable (which would make our sample size of 50 falls within this range) while others rely more on the Kaiser-Meyer-Olkin (KMO) sampling adequacy. In this study, the KMO sampling accuracy was 0.8 which is generally regarded as 'meritorious' although values 0.9 and higher are generally regarded as excellent. Nevertheless, there is a need for further research with a larger sample size. Despite this limitation, the study reveals the appropriateness of the Social Integration Scale for use among patients with schizophrenia in a non-western setting with few modifications for cultural appropriateness [22-29].

\section{Conclusion}

Patients with Schizophrenia have low levels of social integration into the community. It is important as part of routine care to measure the level of social integration because the goal of care is not just provision of medications for symptom remission but rather recovery which involves reintegration into the society and improving their quality of life. In a non-western setting like Nigeria, the Social Integration Scale is a valid measure of social integration among patients with Schizophrenia, and measures community participation and belongingness, giving and receiving help, connectedness, and initiation of social interactions.

\section{References}

1. Brissette I, Cohen S, Seeman TE (2000) Measuring social integration and social networks. Soc Support Meas Interv A Guid Heal Soc Sci 53: 85.
2. Cohen S, Doyle WJ, Skoner DP, Rabin BS, Gwaltney JM (1997) Social ties and susceptibility to the common cold. Jama. 277: 1940-1944.

3. Welin L, Larsson B, Svardsudd K, Tibblin B, Tibblin G (1992) Social network and activities in relation to mortality from cardiovascular diseases, cancer and other causes: a 12 year follow up of the Study of Men Born in 1913 and 1923. J Epidemiol Community Health 46: 127-132.

4. House JS, Robbins C, Metzner HL (1982) The association of social relationships and activities with mortality: Prospective evidence from the tecumseh community health study. Am J Epidemiol 116: $123-140$

5. Hanson BS, Isacsson SO, Janzon L, Lindell SE (1989) Social network and social support influence mortality in elderly men. Am J Epidemiol 130: 100-111.

6. Berkman LF, Syme SL (1979) Social networks, host resistance, and mortality: a nine-year follow-up study of Alameda County residents. Am J Epidemiol 109: 186-204.

7. Henderson S, Duncan-Jones P, Byrne DG, Scott R (1980) Measuring social relationships the interview schedule for social interaction. Psychol Med 10: 723-734.

8. Aubry T, Myner J (1996) Community integration and quality of life: a comparison of persons with psychiatric disabilities in housing programs and community residents who are neighbors. Can J Community Ment Heal Rev Can Sante Ment Communaut 15: 5.

9. Sarason IG, Levine HM, Basham RB, Sarason BR (1983) Assessing social support: The social support questionnaire. J Pers Soc Psychol 44: 127.

10. Koenig HG, Westlund RE, George LK, Hughes DC, Blazer DG, et al. (1993) Abbreviating the Duke Social Support Index for use in chronically ill elderly individuals. Psychosomatics 34: 61-69.

11. Brookings JB, Bolton B (1988) Confirmatory factor analysis of the interpersonal support evaluation list. Am J Community Psychol 16: 137-47.

12. Cutrona CE, Russell DW (1987) The provisions of social relationships and adaptation to stress. Adv Pers relationships 1 : 37-67.

13. Ware NC, Hopper K, Tugenberg T, Dickey B, Fisher D (2007) Connectedness and citizenship: Redefining social integration. Psychiatr Serv 58: 469-474.

14. Ware NC, Hopper K, Tugenberg T, Dickey B, Fisher D (2014) A Theory of Social Integration as Quality of Life. Psychiatr Serv 59: 27-33.

15. Wong Y-LI, Matejkowski J, Lee S (2011) Social integration of people with serious mental illness: Network transactions and satisfaction. J Behav Health Serv Res 38: 51-67.

16. Kay SR, Fiszbein A, Opler LA (1987) The positive and negative syndrome scale (PANSS) for schizophrenia. Schizophr Bull 13: 261-76.

17. TW Group (1998) The World Health Organization quality of life assessment (WHOQOL): development and general psychometric properties. Soc Sci Med 46: 1569-1585.

18. Skevington SM, Lotfy M, O'Connell KA (2004) The world health organization's WHOQOL-BREF quality of life: psychometric properties and results of the international field trial. Qual Life Res 13: 299-310. 
19. SAS Institute. SAS versión 9.4. SAS Institute Inc. 2012.

20. Leff J, Sartorius N, Jablensky A, Korten A, Ernberg G (1992) The International Pilot Study of Schizophrenia: five-year follow-up findings. Psychol Med 221: 131-145.

21. Ohaeri JU (1993) Long-term outcome of treated schizophrenia in a Nigerian cohort. Retrospective analysis of 7-year follow-ups. J Nerv Ment Dis 181: 514-516.

22. Cattell RB (1978) The scientific use of factor analysis in behavioural and life sciences.

23. Hair JF, Anderson RE, Tatham R (1998) Multivariate Data Analysis with Readings, 2nd and 4th Ed. New York, NY: Macmillan.

24. Everitt BS (1975) Multivariate analysis: The need for data, and other problems. Br J Psychiatry 126: 237-240.

25. Parsian N, Dunning $T$ (2009) Developing and validating a questionnaire to measure spirituality: A psychometric process. Glob J Health Sci 1: 2-11.
26. Müller S, Kohlmann T, Wilke T (2015) Validation of the adherence barriers questionnaire-An instrument for identifying potential risk factors associated with medication-related nonadherence. BMC Health Serv Res 15: 153.

27. Santos JJA dos, Costa TA da, Guilherme JH, Silva WC da, Abentroth LRL, et al. (2015) Adaptation and cross-cultural validation of the Brazilian version of the Warwick-Edinburgh mental well-being scale. Rev Assoc Med Bras 61: 209-214.

28. Arafat SM (2016) Psychometric validation of the Bangla version of the patient-doctor relationship questionnaire. Psychiatry J.

29. Kaiser HF (1974) An index of factorial simplicity. Psychometrika 39: 31-36. 